\title{
Encontros Bibli: Revista Eletrônica de Biblioteconomia e Ciência da Informação
}

\author{
Comissão Editorial, n. 20, 2005:
}

\author{
Angel Freddy Godoy Viera - UFSC \\ Francisco das Chagas de Souza - Coordenador - UFSC \\ Gleisy Regina Bóries Fachin - Subcoordenadora - UFSC \\ Lígia Café - UFSC \\ Maria Margarete Sell da Mata - UFSC \\ Miriam Vieira da Cunha - UFSC
}

CONSELHO EDITORIAL

Eliany Alvarenga de Araújo - UFPB

Elsa Barber - Universidade de Buenos Aires

Gérard Régimbeau - Université Paul-Sabatier, Toulouse 3 - France

José Augusto Chaves Guiarães - UNESP/Marília

Maria de Fátima Portela Cysne - UFC

Mario Barité - Universidade de la Republica - Montevidéo/Uruguai

Marta Lígia Pomin Valentim - UEL 


\title{
COLABORARAM NESTE NÚMERO COMO AVALIADORES
}

\author{
Aline França de Abreu - UFSC \\ Angel Freddy Godoy Viera - UFSC \\ Araci Isaltina de Andrade Hillesheim - UFSC \\ Bernadete Santos Campello - UFMG \\ Edna Lúcia da Silva - UFSC \\ Eliana Maria dos Santos Bahia - UFSC \\ Estera Muszkat Menezes - UFSC \\ Fernanda de Sales - UDESC \\ Francisca Rasche - UFSC \\ Francisco das Chagas de Souza - UFSC \\ Gisela Eggert Steindel - UDESC \\ Gleisy Regina Bories Fachin - UFSC \\ Gregório Jean Varvakis Rados - UFSC \\ Iara Conceição Bittencourt Neves - UFRGS \\ Lidia Alvarenga -UFMG \\ Ligia de Arruda Café - UFSC \\ Magda Chagas Pereira - UFSC \\ Marcelo Bax - UFMG \\ Maria Inês Tomaél - UEL \\ Maria Lourdes Blatt Ohira - UDESC \\ Maria Margarete Sell da Mata - UFSC \\ Marta Ligia Pomin Valentim - UEL \\ Miguel Angel Márdero Arellano - IBICT \\ Oswaldo Francisco de Almeida Junior - UEL \\ Othon Jambeiro - UFBA \\ Patrícia Zeni Marchiori - UFPR \\ Regina Célia Baptista Belluzzo - USC \\ Renata Gonçalves Curty - GRITES - UFSC \\ Rildeci Medeiros - UFRN \\ Rosângela Schwarz Rodrigues - UFSC \\ Sandra Lúcia Rebel Gomes - UFF \\ Ursula Blattmann - UFSC \\ Wanda Aparecida Machado Hoffmann - UFSCAR \\ Yolanda Flores e Silva - UNIVALI
}

\section{A Revisão por pares (Peer Review) do ENCONTROS BIBLI}

ENCONTROS BIBLI publica artigos e divulga resenhas de livros. Os Artigos submetidos ao Editor são encaminhados para a apreciação de três pareceristas integrantes do Conselho Editorial, Comissão Editorial ou convidados “ad hoc”. As Resenhas submetidas ao Editor são encaminhadas à apreciação de dois pareceristas. Neste processo, os originais são lidos inicialmente pelo Editor que, se considerar estarem de acordo com a linha editorial geral, os remeterá para os pareceristas. 
Os originais submetidos ao ENCONTROS BIBLI deverão seguir, obrigatoriamente, as INSTRUÇÕES PARA AUTORES, a fim de preservar a característica acadêmica da publicação, sua padronização e seu reconhecimento entre pares. Tendo em vista sua periodicidade estar restrita a duas edições anuais, uma dentro do primeiro e outra dentro do segundo semestre de cada ano, far-se-á sempre o esforço para que os originais recebidos até o final de novembro de cada ano possam ser editados para publicação no primeiro número do ano seguinte e os originais recebidos até o final de junho de cada ano possam ser editados para publicação no segundo número do ano, para tanto, é incluído nos artigos a data de recebimento dos mesmos. Embora isto seja uma intenção, originais que careçam de alterações por seus autores poderão modificar este objetivo. A necessidade de cuidados editoriais rigorosos, que implicam um processo de análise cuidadoso, resulta do fato de que periódicos eletrônicos acadêmicos devem seguir os mesmos critérios de qualidade que se costuma adotar para a edição de periódicos publicados em formatos e suporte tradicionais.

\title{
EXPEDIENTE
}

\author{
Encontros Bibli: Revista Eletrônica de Biblioteconomia e Ciência da \\ Informação é publicada pelo Departamento de Ciência da Informação e \\ pelo Programa de Pós-Graduação em Ciência da Informação, da \\ Universidade Federal de Santa Catarina, disponibilizado na WWW em \\ 06/05/1996, com publicação semestral.
}

Encontra-se indexado no: REDALYC / LATINDEX

Webmaster Copyright @1996 ENCONTROS BIBLI/CIN/PGCIN/UFSC Atualizada em 05/10/2005 


\section{EQUIPE DE TRABALHO}

\section{Angel Freddy Godoy Viera - CIN/UFSC / Gleisy Regina Bories Fachin - CIN/UFSC}

A publicação Encontros Bibli: revista de Biblioteconomia e Ciência da Informação, recebe artigos inéditos de Biblioteconomia e Ciência da Informação, de caráter opinativo, fundamentados em revisão de literatura ou de caráter científico, fundamentados em pesquisas e/ou relatos de experiências.

Os artigos e demais trabalhos publicados no Encontros Bibli: revista de Biblioteconomia e Ciência da Informação, passam a ser propriedade da revista. Sua reimpressão, total ou parcial, fica sujeita à expressa menção da precedência de sua publicação neste periódico, citando-se a edição e data dessa publicação. Para efeitos legais, deve ser consignada a fonte de publicação original. Informase, também, que os originais não serão devolvidos aos autores.

Atualizada em 05/10/2005 


\title{
FICHA CATALOGRÁFICA
}

\author{
Elaborada pelas Professoras Araci Isaltina de Andrade Hillsheim-CRB-14/519 e \\ Maria Margarete Sell da Mata-CRB-14/106
}

\begin{abstract}
Encontros Bibli : Revista Eletrônica de Biblioteconomia e Ciência da Informação / Departamento de Ciência da Informação, Universidade Federal de Santa Catarina. -- n.1 (maio 1996). -- Florianópolis : Universidade Federal de Santa Catarina, Departamento de Ciência da Informação, 1996-

Semestral.

Publicado com o sub-título: Revista de Biblioteconomia e Ciência da Informação, n. 1 a 13.

n. 1 até n. 6, editados pelo Departamento de Biblioteconomia e Documentação. A partir de

1999, editado pelo Departamento de Ciência da Informação.

Disponível na Internet: <http://ced.ufsc.br/bibliote/encontro/>.

A partir do número 11, de junho de 2001, disponível em: http://www.encontrosbibli.ufsc.br/

A partir do número $15,1^{\circ}$ semestre de 2003 , passou a ter sua data por semestre.

A partir do número $16,2^{\circ}$ semestre de 2003 , passou a ter a co-edição do Programa de Pós-Graduação em Ciência da Informação/CIN/UFSC.

1. Biblioteconomia - Periódicos. 2. Ciência da Informação - Periódicos. I. Universidade Federal de Santa Catarina. Departamento de Ciência da Informação. CDD (21.ed.) 020.5
\end{abstract}

Disponibilizado na WWW em 05/10/2005.

Enc. Bibli: R. Eletr. Bibliotecon. Ci. Inf., ISSN 1518-2924, Florianópolis, Brasil. 